\title{
The power of gold: a tip for an uncrossable ostial lesion
}

\author{
Krzysztof K. Ściborski, Michał Furdal, Adam Porada, Paweł Szymkiewicz, Artur Telichowski
}

Department of Cardiology, $4^{\text {th }}$ Military Hospital, Wroclaw, Poland

Adv Interv Cardiol 2021; 17, 2 (64): 226-227

DOI: https://doi.org/10.5114/aic.2021.107506

Uncrossable lesions are lesions that cannot be crossed with a balloon or microcatheter after guide wire crossing. They constitute a considerable challenge in coronary interventions and are associated with poor outcome in patients undergoing rotational atherectomy (RA) [1].

Most of the documented methods cannot be applied in true aorto-ostial lesions with severe stenosis. Such lesions require a nonstandard approach that has not been precisely described in any expert documents so far [2-4].

In our case, coronary angiography revealed subtotal occlusion of the right coronary artery ostium (Figure $1 \mathrm{~A}$ ). Ad hoc percutaneous coronary intervention ( $\mathrm{PCl}$ ) failed due to inability to cross the lesion with a balloon catheter $(1.5 \times 10 \mathrm{~mm}$, Solarice, Medtronic). Three days later, an attempt at PCl with RA was made. However, we failed to advance a tapered, low-profile tip microcatheter (FineCross MG, Terumo) or a low-crossing profile balloon (Ryurei, $1.0 \times 5 \mathrm{~mm}$, Terumo), despite the exchange of a guide catheter. Attempts at direct insertion of the RotaWire Floppy (Boston Scientific) guide wire with Finecross microcatheter support were also unsuccessful. Balloons negotiated as far as possible into the lesion and inflated at high pressure also did not produce desirable effects. Finally, after introducing a guide wire (Fielder XT, Asahi) into the distal part of the vessel, we decided to use a microcatheter with a gold-plated, threaded metallic tip (Turnpike Gold Catheter, Teleflex) in an attempt to screw it through and anchor at the beginning of the lesion, which proved to be feasible (Figure $1 \mathrm{~B}$ ). The stable catheter position achieved by the screw-like advance- ment of the distal end of the catheter tip into the lesion allowed a successful passage of the RotaWire Extra Support guide wire, and RA was performed using a 1.25-mm burr (Figure $1 \mathrm{C}$ ). Next, standard balloon angioplasty and stent implantation were performed (Figure $1 \mathrm{D}$ ).

Adequate guide catheter support is the key to successful PCl. However, in true ostial coronary lesions with critical stenosis, the choice of the catheter is guided by the type of the lesion rather than the operator's preference. The usefulness of the mother-in-child approach or various anchoring techniques is also limited in such cases. RA requires a special guide wire that may be unable to penetrate the uncrossable lesion. An attempt at plaque modification using even a dedicated microcatheter with well-documented efficacy in uncrossable lesions, such as Tornus (Asahi), may prove unsuccessful. This is because even though it was designed with threads to screw into the lesion, the outer coils are placed behind the tapered tip, and for the screwing to be effective, at least minimal support is needed in order to insert the tip into the lesion as far as the edge of threads, which could be too much for extremely tight aorto-ostial lesions. Therefore, in a clinical scenario of extremely tight ostial lesions without adequate support, the use of a unique Turnpike Gold catheter may prove valuable because it has an additional polished threaded gold tip capable of screwing through resistant lesions, thus enhancing penetrative capability.

\section{Conflict of interest}

The authors declare no conflict of interest.

\section{Corresponding author:}

Krzysztof K. Ściborski PhD, Department of Cardiology, $4^{\text {th }}$ Military Hospital, 5 Weigla St, 50-981 Wroclaw, Poland, phone: +48509289287 ,

e-mail: k.sciborski@op.pl

Received: 2.02.2021, accepted: 4.03.2021. 

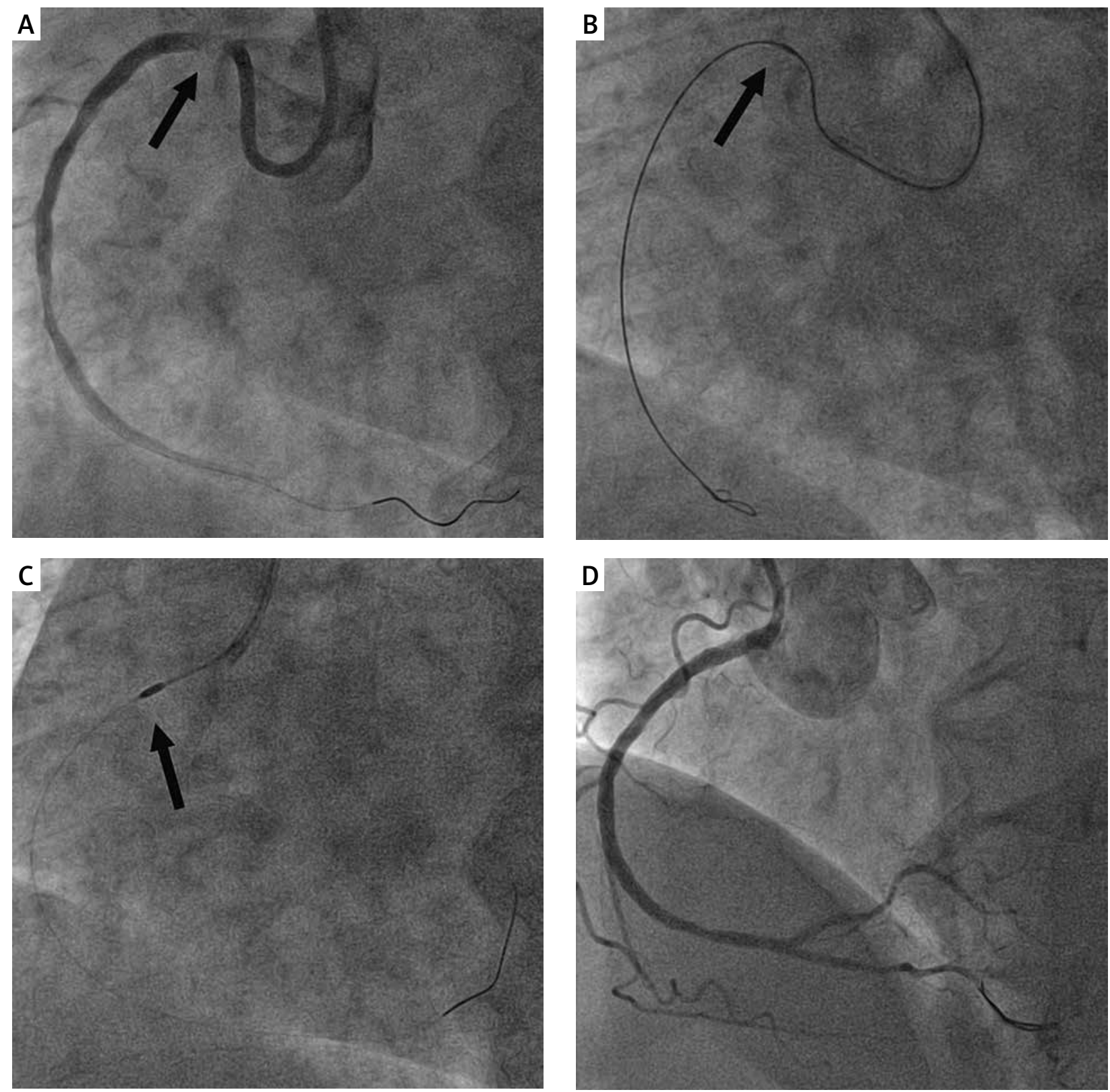

Figure 1. Angiography imaging: A - tight stenosis of the right coronary artery ostium, B - Turnpike Gold catheter screwed into the right coronary artery ostium, $\mathbf{C}$ - rotablation of the right coronary artery ostium, D - final outcome

\section{References}

1. Kübler P, Zimoch W, Kosowski M, et al. Novel predictors of outcome after coronary angioplasty with rotational atherectomy. Not only low ejection fraction and clinical parameters matter. Adv Interv Cardiol 2018; 14: 42-51.

2. Elrayes MM, Xenogiannis I, Nikolakopoulos I, et al. An algorithmic approach to balloon-uncrossable coronary lesions. Catheter Cardiovasc Interv 2021; 97: E817-25.

3. Dobrzycki S, Reczuch K, Legutko J, et al. Rotational atherectomy in everyday clinical practice. Association of Cardiovascular Interventions of the Polish Society of Cardiology (Asocjacja Interwencji Sercowo-Naczyniowych Polskiego Towarzystwa Kardio- logicznego - AISN PTK): expert opinion. Kardiol Pol 2018; 76 : 1576-84.

4. Fang $\mathrm{HY}$, Lee $\mathrm{CH}$, Fang $\mathrm{CY}$, et al. Application of penetration device (Tornus) for percutaneous coronary intervention in balloon uncrossable chronic total occlusion-procedure outcomes, complications, and predictors of device success. Catheter Cardiovasc Interv 2011; 78: 356-62. 